\title{
Evaluation of Zoonotic Disease and Exposures in Persons Working with Marine Mammals
}

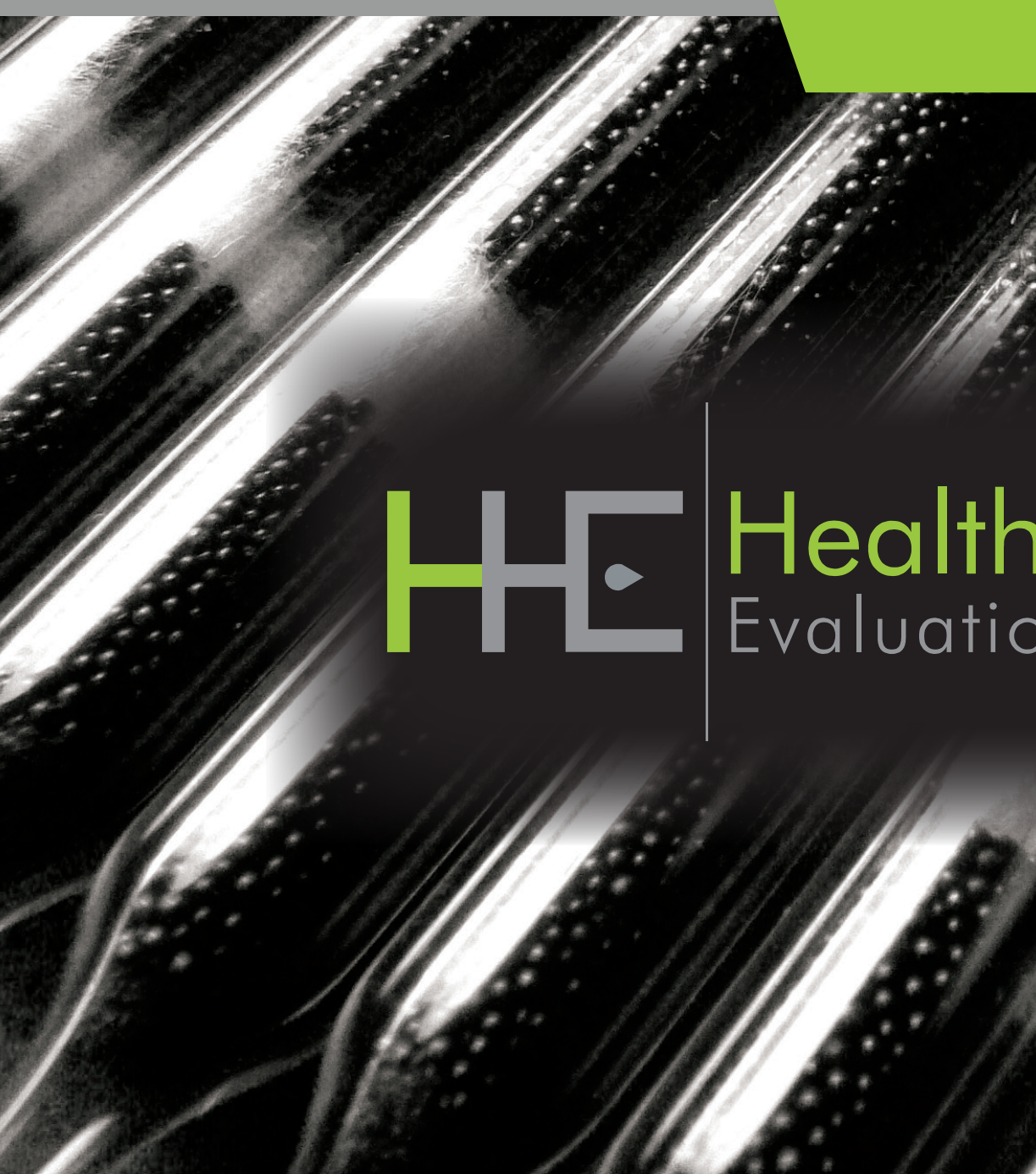

Report No. 2011-0105-3173

April 2013

John Gibbins, DVM, MPH

R. Todd Niemeier, MS, CIH

Marie A. de Perio, MD

Charles Mueller, MS 


\section{Contents}

Highlights.............................................................

Abbreviations .............................................. iv

Introduction .................................................... 1

Methods ........................................................... 2

Results ................................................................... 4

Discussion ........................................................ 11

Conclusions .................................................. 15

Recommendations.................................. 16

Appendix A ................................................ 19

Appendix B............................................... 22

Appendix C................................................. 24

References.................................................... 26

Acknowledgements................................ 31

The employer is required to post a copy of this report for 30 days at or near the workplace(s) of affected employees. The employer must take steps to ensure that the posted report is not altered, defaced, or covered by other material.

The cover photo is a close-up image of sorbent tubes, which are used by the HHE Program to measure airborne exposures. This photo is an artistic representation that may not be related to this Health Hazard Evaluation. 


\section{Highlights of this Evaluation}

The Health Hazard Evaluation Program received a request from a marine mammal rescue and rehabilitation center in California. Managers were concerned about the potential exposure of employees and volunteers to zoonotic diseases. Zoonotic diseases can be transmitted from animals to humans.

\section{What We Did}

- We evaluated the main facility and a triage facility in June 2011.

- We surveyed employees and volunteers, which included a questionnaire and serologic tests for evidence of past infection with three bacteria that cause zoonotic disease.

- We observed work practices and personal protective equipment use at both facilities.

- We took ventilation measurements in the headquarters laboratory and harbor seal building.

- We collected air, surface, and bulk dust samples for $C$. burnetti, one of the bacteria that cause zoonotic disease, at both facilities.

\section{What We Found}

- We observed some work practices that may lead to a higher risk of exposure to zoonotic diseases.

- Our evaluation of the blood samples of the 213 participants found little evidence of past infection of employees and volunteers with the organisms that cause leptospirosis, brucellosis, or Q fever.

- All but one of the 130 environmental samples

We evaluated the exposure of marine mammal employees and volunteers to zoonotic diseases by giving them a questionnaire; collecting blood samples for serology; and collecting environmental samples. Even though we found little evidence of past infection in these people, they may still get zoonotic infections. We recommended improved engineering controls in the facility, improved personal protective equipment use, and enhanced training for employees and volunteers. collected were negative for C. burnetii.

- Some employees and volunteers were not wearing the correct personal protective equipment.

- The biological safety cabinet in the headquarters laboratory did not have enough airflow.

- When the ventilation system in the harbor seal area was turned on, air flowed from the harbor seal intensive care unit to other areas of the building. This could lead to a higher risk of exposure to zoonotic agents.

\section{What the Employer Can Do}

- Provide initial training for all volunteers and employees on hand washing, proper personal protective equipment use, and their risks of infection. Provide refresher training at least twice per year.

- Post more signs about hand washing at all facilities. 


\section{What the Employer Can Do (continued)}

- Restrict the number of people at necropsies to limit potential exposure to zoonotic agents.

- Update the respiratory protection program to include facility employees and volunteers who work in the necropsy area.

- Develop a policy to ensure guest researchers who participate in necropsies are enrolled in their organization's respiratory protection program.

- Require use of N95 respirators in addition to standard personal protective equipment during necropsy procedures that generate aerosols or when the likelihood of exposure to zoonotic agents is high.

- Remove carpet from the triage building and replace it with a nonporous surface.

- Do not house harbor seal pups in the harbor seal intensive care unit if they are suspected of having Q fever. House harbor seal pups suspected of having Q fever outside, ideally isolated from other harbor seal pups.

- Make sure that the biological safety cabinets in the headquarters laboratory are certified yearly and meet minimum flow requirements.

\section{What Employees Can Do}

- Wash your hands after exposure to animals or animal areas, even if you were wearing gloves.

- Use personal protective equipment that matches job duties.

- Do not wear personal protective equipment in areas in the triage building where people eat or drink.

- Do not eat or drink in the chart room or other areas where people wear personal protective equipment.

- Report any signs and symptoms of a possible zoonotic infection to your supervisor and seek medical care. Tell your healthcare provider about your duties and exposure to marine mammals. 
Mention of any company or product does not constitute endorsement by NIOSH. In addition, citations to websites external to NIOSH do not constitute NIOSH endorsement of the sponsoring organizations or their programs or products. Furthermore, NIOSH is not responsible for the content of these websites. All web addresses referenced in this document were accessible as of the publication date of this report. 


\section{Abbreviations}

BSC Biological safety cabinet

BSL Biosafety level

CDC Centers for Disease Control and Prevention

CFR Code of Federal Regulations

DNA Deoxyribonucleic acid

ELISA Enzyme-linked immunosorbent assay

fpm Feet per minute

$\mathrm{ft}^{2} \quad$ Square feet

HHE Health hazard evaluation

ICU Intensive care unit

IFA Indirect fluorescent antibody

IgG Immunoglobulin $\mathrm{G}$

IgM Immunoglobulin M

MAT Microagglutination test

NAICS North American Industry Classification System

NASPHV National Association of State Public Health Veterinarians

NIOSH National Institute for Occupational Safety and Health

OSHA Occupational Safety and Health Administration

PCR Polymerase chain reaction

PPE Personal protective equipment

Spp. Species 


\section{Introduction}

The Health Hazard Evaluation (HHE) Program received a request from managers at a marine mammal rescue and rehabilitation center in California. The request concerned the potential for exposure of employees and volunteers to the bacterial pathogens responsible for the zoonotic diseases, Q fever (Coxiella burnetii), brucellosis (Brucella spp.), and leptospirosis (Leptospira spp.). These bacterial pathogens, most commonly associated with ruminants such as cattle, sheep, and goats, are also known to infect marine mammals, but the prevalence of infection in marine mammals and people who work with them is not known.

In June 2011, National Institute for Occupational Safety and Health (NIOSH) investigators visited the center. During the visit, we met with employer, employee, and volunteer representatives to discuss the HHE request. We provided informational fact sheets and website links about Q fever, brucellosis, and leptospirosis. We observed workplace conditions and work processes and practices. We also spoke with employees and volunteers about their job duties. We focused our evaluation on work activities with potential exposures to animals or animal pathogens. We collected questionnaire and serologic data for participants and took environmental samples. In addition to our evaluation at the headquarters facility, part of our team traveled to a satellite triage center to enroll participants in the evaluation and collect environmental samples.

\section{Marine Mammal Rescue and Rehabilitation Center}

At the time of the evaluation, the center was a nonprofit veterinary rehabilitation hospital and educational center focused on the rescue, treatment, and rehabilitation of sick or injured marine mammals. As many as 200 animals at a time were cared for at its multiple facilities, which treated 1,000 animals each year. The center most commonly housed California sea lions, harbor seals, and elephant seals, although dolphins, porpoises, otters, and other species were sometimes cared for as well. Although clinically diagnosed cases of Q fever and brucellosis were reportedly rare at the center, mammals, especially sea lions, were routinely diagnosed with leptospirosis, on the basis of clinical judgment or laboratory diagnosis. Additional information about the epidemiology and clinical characteristics of these bacterial agents in marine mammals and humans is available in Appendices A and B.

The center's facilities included the headquarters facility and three triage facilities along the California coast. These triage facilities assessed the health status of rescued animals and temporarily held animals for release or transport to the headquarters for further treatment.

The headquarters facility had approximately 35 paid employees and 200 regular volunteers. Employees' job tasks included office work; necropsies; animal handling; capturing sick or wounded animals from the beach, water, and docks; releasing animals back into the wild; clinical laboratory work; and facilities maintenance. In addition, employees oversaw the work of volunteers. Volunteers did numerous jobs including office work; staffing the gift shop; educational outreach; preparing animal food; administering medication; handling 
animals; cleaning pens; capturing sick or wounded animals from the beach, water, and docks; and releasing animals back into the wild.

Volunteers at the headquarters facility typically worked one shift a week; shifts usually ran from 7 a.m. to 3 p.m. (day shift) and 6 p.m. to 11 p.m. (night shift). Shift length and number of volunteers per shift varied on the basis of the number of animals at the facility. Several hundred additional volunteers over a 600-mile range, from Mendocino County, California, through San Luis Obispo County, California, were responsible for animal rescue, triage, transportation, release, and education.

\section{Methods}

The purpose of our evaluation was to (1) assess the occupational risk of workers and volunteers to Coxiella burnetii (C. burnetii), Brucella spp., and Leptospira spp.; (2) assess the center's engineering, administrative, and personal protective equipment (PPE) controls; and (3) make recommendations to improve related occupational health practices.

We conducted a serologic survey of center employees and volunteers, observed work practices and PPE use at the headquarters facility and one triage facility, took ventilation measurements in the laboratory and harbor seal area, and collected environmental samples in several areas around the headquarters facility and a triage facility.

\section{Serologic Survey}

Using a cross-sectional study design, we invited all employees and volunteers 18 years old and older working at the headquarters facility and triage facility on the dates of our evaluation to participate in our serologic survey, which consisted of a questionnaire and serum sample. Other volunteers who were not working the week of our visit were also invited to participate. We counted those who volunteered at the headquarters facility and triage facilities or also participated in beach rescue as headquarters volunteers. The questionnaire included personal characteristics; relevant medical history; work duties at the facility and at other job sites, in the case of volunteers and part-time employees; work history; and risk factors for Q fever, brucellosis, and leptospirosis.

After giving informed consent, participants provided a serum sample for us to determine the prevalence of immunologic evidence of past infection with C. burnetii, Brucella spp., and Leptospira spp. All serum samples were analyzed at the laboratories within the Centers for Disease Control and Prevention (CDC) Rickettsial Zoonoses Branch and Bacterial Special Pathogens Branch in Atlanta, Georgia. Details about serologic laboratory methods are available in Appendix C.

To determine seroprevalence, the following case definitions were used:

- Brucella seropositivity was defined as a Brucella total antibody titer $\geq 1: 160$ by the Brucella MAT. 
- Leptospirosis seropositivity was defined as a Leptospira agglutination titer $\geq 1: 100$ by the Leptospira MAT.

- Q fever seropositivity was defined as a phase I or phase II immunoglobulin G (IgG) titer $\geq 1: 32$ by IFA for IgG antibodies.

Participants below these cutoff levels either had not been infected with the organism in the past, or their titer was too low to determine if they were previously infected; titers can wane over time in some individuals. Phase I IgG antibody levels for C. burnetii $\geq 1: 800$ were considered suggestive of chronic Q fever infection. Participants were notified of their individual serological results by letter in September 2011.

SAS Version 9.2 software (SAS Institute Inc., Cary, North Carolina) was used for statistical analysis. We calculated prevalence ratios and used $2 \mathrm{X} 2$ analyses with Fisher's exact test to evaluate possible relationships between C. burnetii seropositivity and participants' characteristics or exposures. Prevalence ratios greater than 1 indicate that the participants with the characteristic or exposure had a prevalence of seropositivity greater than that for the participants without the characteristic or exposure. Results with P values $\leq 0.05$ were considered statistically significant.

\section{Observation of Work Practices}

To understand potential exposures to zoonotic agents, we observed work practices at the headquarters facility and one of the triage facilities. We observed employees and volunteers during daily cleaning and feeding in animal pens, necropsies, maintenance activities, laboratory activities, and animal handling and transportation. We noted PPE use among employees and volunteers during these work activities.

\section{Ventilation Assessment}

We evaluated the airflow in two biological safety cabinets (BSCs) in the laboratory at the headquarters facility. We used a TSI VelociCalc ${ }^{\circledR}$ Plus air velocity meter, model 8386A (TSI, Inc., Shoreview, Minnesota) to measure air velocity at the face of each BSC. We collected equally spaced air velocity measurements at approximately 12-inch intervals across the face of the BSC in the microbiology laboratory and at approximately 18 -inch intervals across the face of BSC in the clinical laboratory. In addition, we used smoke tubes to visualize the direction of airflow in the harbor seal intensive care unit (ICU) (Gastec Corporation, Kanagawa, Japan).

\section{Environmental Sampling}

We collected 37 air samples including 23 personal breathing zone and 14 area samples, 69 surface samples ( 25 vacuum samples for porous surfaces and 44 sponge wipes for nonporous surfaces), and 10 bulk dust samples to determine the presence of $C$. burnetii in several areas 
within the headquarters facility and triage facility. Details of environmental sampling and analysis methods are available in Appendix C.

\section{Results}

\section{Serologic Survey}

The 222 participants who completed our questionnaire included 35 paid employees, 184 volunteers, and 3 participants who reported working both as a paid employee and a volunteer. Among the 222 participants, 198 (89\%) worked at the headquarters facility, 24 (11\%) worked at the triage facility, and $213(96 \%)$ reported ever caring for or handling marine mammals. The median age of participants was 45 years (range: 18-77 years). Of the 222 survey participants, 164 (74\%) were female. Survey participants had worked or volunteered at the headquarters facility or triage facility for a median of 2.4 years (range: 2 days -35 years), a median of 40 weeks per year (range: 1-52 weeks per year), and a median of 8 hours a week (range: 2-70 hours per week). In addition, 213 (96\%) reported caring for marine mammals at the center. Eleven participants reported being veterinarians.

The work and PPE practices of the 213 survey participants who reported caring for marine mammals are shown in Table 1. Of these 213 participants, 194 (91\%) reported always washing their hands before eating at work, while 61 (29\%) reported always changing their clothes before leaving work. Regarding PPE use, none of these 213 participants reported never wearing gloves, 3 (1\%) reported never wearing rubber boots, and $15(7 \%)$ reported never wearing a raincoat or waterproof suit while working at the center. Only 154 (73\%) reported always wearing gloves, and $88(41 \%)$ reported always wearing raincoats/waterproof suits. However, our discussions with employees and volunteers as well as observations of

Table 1. Frequency of work practices reported by employees and volunteers who also reported caring for marine mammals

\begin{tabular}{lcccc}
\hline & \multicolumn{4}{c}{ Number (\%) of participants, $\mathrm{n}=211-213^{*}$} \\
Work practice & Always & Most of the time & Some of the time & Never \\
\hline Wash hands before eating & $194(91)$ & $17(8)$ & $2(1)$ & $0(0)$ \\
Change clothes before eating & $63(30)$ & $37(17)$ & $53(25)$ & $59(28)$ \\
Shower before eating & $7(3)$ & $10(5)$ & $38(18)$ & $158(74)$ \\
Change clothes before leaving work & $61(29)$ & $17(8)$ & $55(26)$ & $80(38)$ \\
Shower before leaving work & $2(1)$ & $5(2)$ & $16(8)$ & $190(89)$ \\
PPE use: & & & & \\
$\quad$ Gloves & $154(73)$ & $47(22)$ & $10(5)$ & $0(0)$ \\
$\quad$ Rubber boots & $146(69)$ & $41(19)$ & $23(11)$ & $3(1)$ \\
Raincoat/waterproof suit & $88(41)$ & $58(27)$ & $52(24)$ & $15(7)$ \\
\hline
\end{tabular}

*Sample sizes vary because of missing values. 
work tasks revealed that some participants did additional tasks at the facility that did not involve direct animal care or require PPE use, such as giving tours, participating in meetings and rounds, and office work.

Of the 77 participants who reported having contact with dead marine mammal tissues, fluids, and blood during necropsies, 46 (60\%) reported never wearing goggles, 42 (55\%) reported never wearing masks, and $68(88 \%)$ reported never wearing respirators during their work.

Of the 222 participants who completed our questionnaire, $213(96 \%)$ consented and provided a serum sample. All 213 participants providing a serum sample were considered negative for brucellosis infection using the Brucella total antibody titer of $\geq 1: 160$. Thirty-eight $(18 \%)$ participants had total antibody titers between 1:20 and 1:80, which might indicate past exposure with Brucella spp., and 175 (82\%) had negative Brucella titers. None of the 221 participants reported ever being diagnosed with brucellosis.

Two (1\%) participants had titers that were considered positive for past leptospirosis infection. None of the 221 participants reported ever being diagnosed with leptospirosis. The two seropositive participants were part-time volunteers who had been at the center for at most 2 months. Both were female, worked in the topside area, and reported exposures to other potential sources of leptospirosis including working with animals before working at this center and participating in outdoor water recreational activities such as water sports, swimming, and paddling, excluding swimming pool use. Of the participants, 50\% also reported working with animals before working at this center, and $92 \%$ reported participating in outdoor water recreational activities.

Nine (4\%) participants demonstrated antibody titers to $C$. burnetii that indicated past infection with $\mathrm{Q}$ fever. None had titers suggestive of chronic Q fever infection. The median age of the nine seropositive participants was 40 years (range: 27-60 years); eight were female. Three were paid employees, and six were volunteers. Eight reported ever caring for or handling marine mammals at the center. Only one participant, a veterinarian, reported ever being diagnosed with Q fever, and this occurred in 2004 prior to working at the center.

Characteristics associated with $C$. burnetii seropositivity are shown in Table 2. Characteristics and exposures that were significantly associated with positive serology for $C$. burnetii were being a veterinarian (prevalence ratio: 11.6, $P<0.01$ ); self-reported exposure to feral swine blood or fluids in past year (prevalence ratio: $11.9, P=0.01$ ); and consumption of raw (unpasteurized) dairy products, such as raw milk or cheese, within the last year (prevalence ratio: $4.4, P=0.03$ ). 
Table 2. Frequency and prevalence of $C$. burnetii seropositivity in participants

\begin{tabular}{|c|c|c|c|c|}
\hline Characteristic or exposure & $\begin{array}{l}\text { Participants with } \\
\text { characteristic } \\
\text { or exposure } \\
\text { Seropositive (\%) }\end{array}$ & $\begin{array}{l}\text { Participants without } \\
\text { characteristic } \\
\text { or exposure } \\
\text { Seropositive (\%) }\end{array}$ & $\begin{array}{l}\text { Prevalence } \\
\text { ratio }\end{array}$ & $P$ value \\
\hline Female & $8 / 157(5)$ & $1 / 56(2)$ & 2.9 & 0.45 \\
\hline Veterinarian & $4 / 11(36)$ & $5 / 159(3)$ & 11.6 & $<0.01$ \\
\hline $\begin{array}{l}\text { Cared for or handled } \\
\text { pinnipeds (seals, fur seals, } \\
\text { sea lions) }\end{array}$ & $8 / 204(4)$ & $1 / 9(11)$ & 0.4 & 0.33 \\
\hline $\begin{array}{l}\text { Cared for or handled } \\
\text { cetaceans (whales, } \\
\text { dolphins, porpoises }\end{array}$ & $4 / 78(5)$ & $4 / 133(3)$ & 1.7 & 0.47 \\
\hline $\begin{array}{l}\text { Cared for or handled sea } \\
\text { otters }\end{array}$ & $3 / 58(5)$ & $6 / 154(4)$ & 1.3 & 0.71 \\
\hline $\begin{array}{l}\text { Contact with live marine } \\
\text { mammals, tissues, or blood }\end{array}$ & $9 / 200(5)$ & $0 / 13(0)$ & Undefined & $>0.99$ \\
\hline $\begin{array}{l}\text { Contact with dead marine } \\
\text { mammals, tissues, fluids } \\
\text { and blood }\end{array}$ & $7 / 162(4)$ & $2 / 51(4)$ & 1.1 & $>0.99$ \\
\hline $\begin{array}{l}\text { Contact with pregnant/ } \\
\text { newborn/birth products } \\
\text { from marine mammal }\end{array}$ & $7 / 132(5)$ & $2 / 81(2)$ & 2.1 & 0.49 \\
\hline $\begin{array}{l}\text { Clean or repair equipment } \\
\text { or enclosures }\end{array}$ & $7 / 197(4)$ & 2/16 (13) & 0.3 & 0.14 \\
\hline $\begin{array}{l}\text { Ever lived within } 5 \text { miles of } \\
\text { sheep, goat, cattle }\end{array}$ & $5 / 84(6)$ & $4 / 129(3)$ & 1.9 & 0.32 \\
\hline $\begin{array}{l}\text { Exposed to feral swine } \\
\text { blood or fluids in past } \\
\text { year }\end{array}$ & $2 / 5(40)$ & $7 / 208(3)$ & 11.9 & 0.01 \\
\hline $\begin{array}{l}\text { Consumed raw dairy in } \\
\text { past year }\end{array}$ & $5 / 47(11)$ & $4 / 166(2)$ & 4.4 & 0.03 \\
\hline
\end{tabular}

\section{Observation of Work Practices and Personal Protective Equipment Use}

\section{Pen Cleaning and Animal Feeding}

At the time of our evaluation, the headquarters facility had a topside area that contained 18 outdoor pens to house elephant seals and sea lions. In this area, volunteers usually worked in groups of two or three. All of the animal pens were cleaned weekly or when animals were permanently moved from the pens. A $10 \%$ household bleach solution was poured onto the concrete and scrubbed with a push broom (Figure 1). After scrubbing, the area was rinsed with water via a hose. Walkways within the pen areas were disinfected daily. Individuals 
working in this area wore chest-high waterproof overalls, rubber boots, and reusable rubber or disposable powder-free natural latex gloves for all activities.

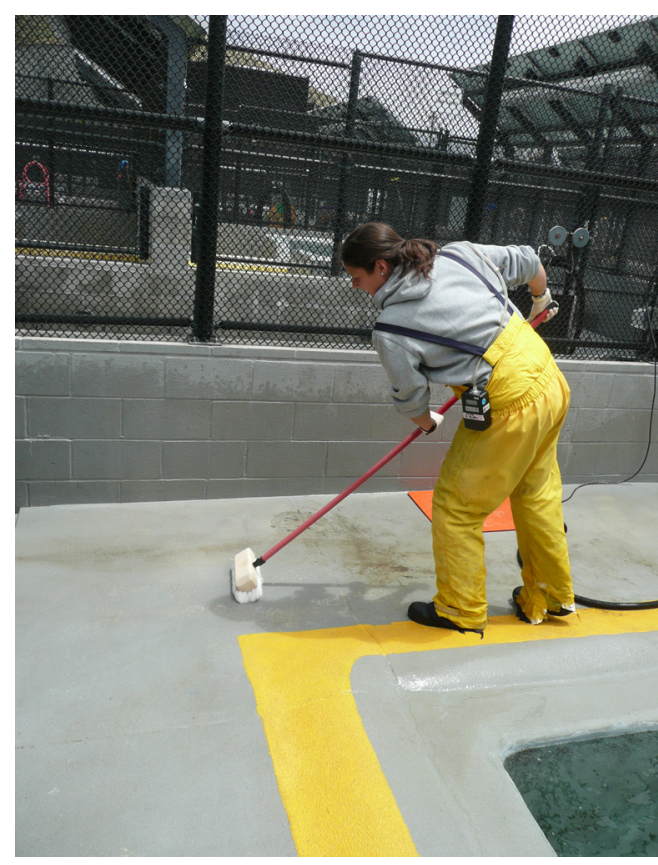

Figure 1. Volunteer cleaning an animal pen at the headquarters facility wearing PPE.
We observed volunteers taking their breaks, eating, and drinking in the chart room. We also observed individuals entering the chart room while still wearing overalls and boots. Some volunteers at the headquarters facility told us that they did not always wash their hands after handling animals because they wore gloves during animal handling procedures.

A separate area of the headquarters facility housed harbor seals. This area consisted of outdoor and indoor caged areas. The outdoor area had 10 small cages without pools to house individual harbor seals and four larger pens with concrete pads and pools to house groups of harbor seals. Three additional pens with pools were adjacent to the topside area for animals ready for release (Figure 2 ). The harbor seal area was also served by a separate building that housed a chart room, fish kitchen, x-ray room, surgery suite, and harbor seal ICU. The harbor seal ICU had 11 indoor cages to house abandoned harbor

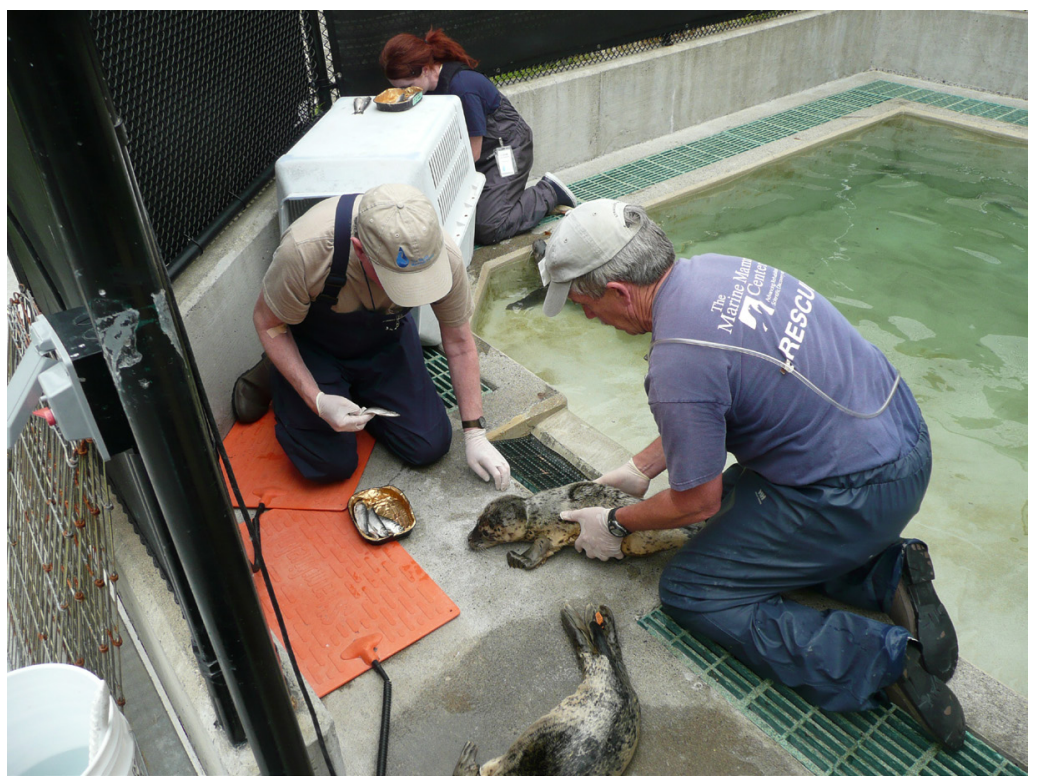
seal pups until they were well enough to be moved outside. Volunteers in this area usually worked in groups of up to five. The same cleaning and feeding methods used in the topside area were used in this area. We observed the same use of PPE in this area as in topside. Boot wash stations that contained a $10 \%$ household bleach solution were located throughout both areas.

Figure 2. Volunteers feeding harbor seal pups at the headquarters facility. 


\section{Triage Facility}

The triage facility had eight outdoor pens and four indoor pens in a garage area attached to a one-story office building. The triage facility was staffed by one employee and several volunteers. The office building had a common area, kitchen, bathroom, three offices, and a separate kitchen for animal medication and food processing. The office area was carpeted throughout, except in the garage and animal kitchen. Only one animal was present at the triage facility during our evaluation, and it was housed in an outdoor pen. PPE worn by volunteers and employees at the triage facility depended on the work activities. On the day of our evaluation, employees and volunteers wore leather work gloves or disposable powder-free natural latex gloves while handling the sea lion or its cage and rubber boots while performing wet work. According to employees and volunteers, they wore chest-high waterproof overalls when needed. They reported that they sometimes wore the overalls in the office area after handling the animals or cleaning cages.

\section{Animal Transportation}

At the time of our evaluation, when animals were rescued from the beach, they were corralled into crates using wooden planks. The crates were placed into either the bed of a pickup truck or the back of a cargo van, and the animals were then transported to the main facility or a triage facility (Figure 3). The cargo vans had passenger compartments that were separated from the cargo area by a metal plate with an access door. The air was shared between the two areas of the van. We observed a van delivering a sea lion pup housed in a crate and noted extensive fecal contamination in the back of the van after the animal was removed. According to volunteers, the vans were usually cleaned with water if they were heavily soiled. We did not observe this cleaning activity. The inside of the crate was also heavily soiled with fecal matter.

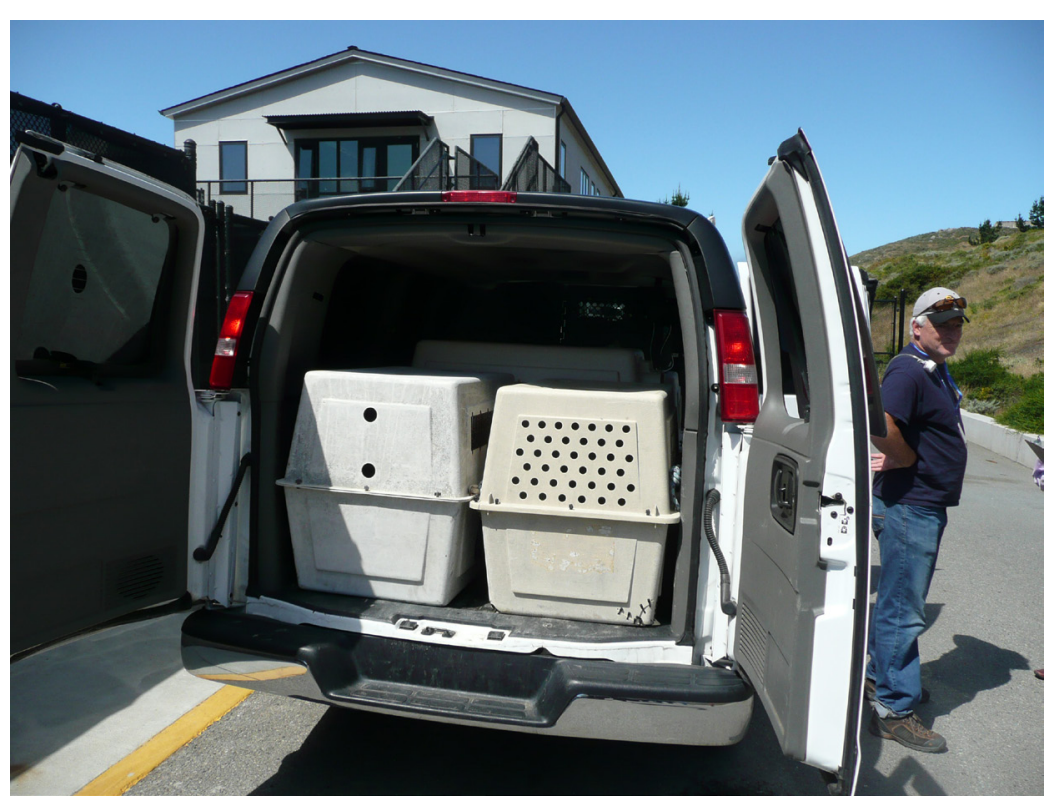

Figure 3. Animals to be released are loaded into a cargo van at the headquarters facility.
After the sea lion was removed from the crate, the crate was washed with water and disinfected with a $10 \%$ household bleach solution. The volunteers removing the crate from the van wore powder-free natural latex or leather work gloves when handling and washing the crate.

Rehabilitated animals housed at the facility were often released in groups. Animals were placed in crates, loaded into the back 
of pickup trucks and vans, and driven approximately 2 hours to a secluded beach for release. Some personnel wore powder-free natural latex gloves or work gloves when handling the animal cages during the release; others wore no gloves. Personnel wore no other PPE during the release.

\section{Filter Room Maintenance}

The salt water system that provided pool water for the marine mammals at the facility was a $100 \%$ recirculating system. The filtration room was in a completely enclosed decommissioned underground missile silo. Water was circulated from the pools to drum filters, sand filters, ozone treatment, and foam fractionators. After filtration, the water was sent to storage tanks, where it was kept until it was needed to refresh the pools. The drum filters were opened and sprayed once per week with a water lance. Sand filters and foam fractionators were cleaned one or two times per year with a hose or water lance. Though we did not see these activities, according to maintenance staff, nitrile gloves were typically worn during cleaning activities. Though maintenance staff did not wear respiratory protection during cleaning activities in the filtration room, some maintenance staff were included in the respiratory protection program. The written respiratory protection program included medical evaluations and fit testing with half-mask air purifying respirators equipped with particulate and vapor cartridges for wear during other work tasks such as painting or dust generating activities.

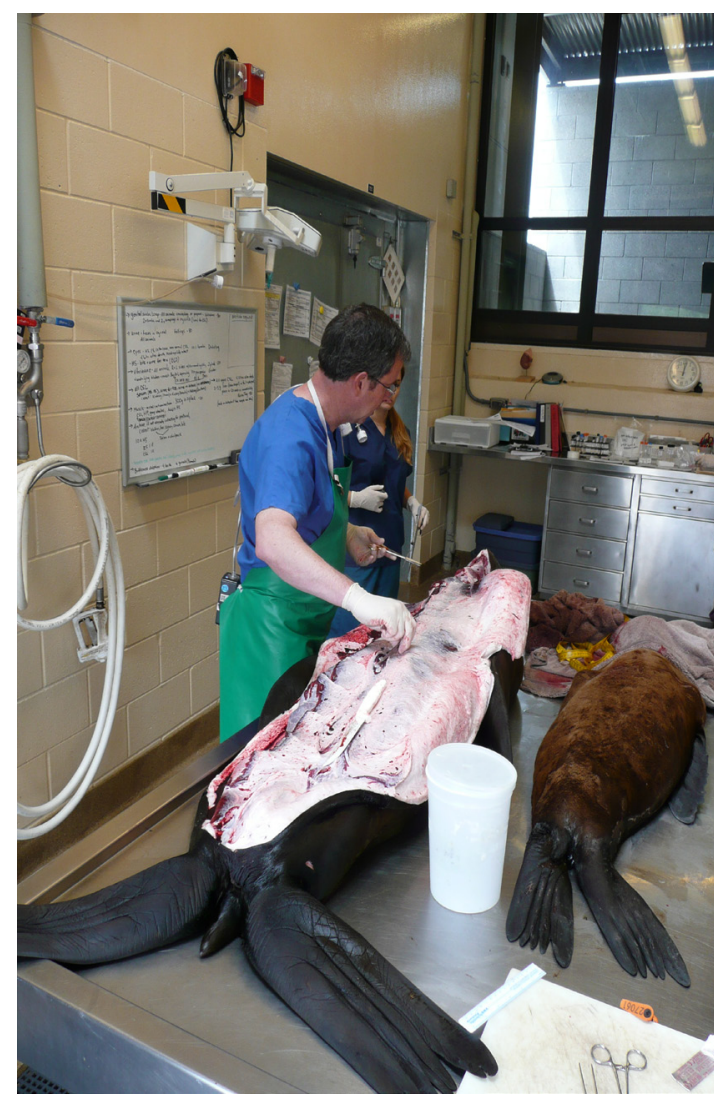

Figure 4. Veterinary staff conducting a necropsy on two marine mammals at the headquarters facility.

\section{Necropsy Procedures}

Necropsies were performed at the headquarters facility in a room approximately 12 feet wide by 20 feet long (Figure 4). A single exhaust fan located approximately 20 feet above the necropsy table was operational but rarely used. One wall of the room consisted of a large garage door that opened to the outside. Necropsies were usually performed with this garage door open. The necropsy room also had an adjacent changing room. A foot bath containing a $0.26 \%$ calcium hypochlorite solution was located between the changing room and the necropsy area. We observed employees wearing short-sleeved scrubs, aprons, rubber boots, and a single layer of powder-free latex gloves during all necropsy procedures described below. NIOSH-approved N95 filtering facepiece respirators were available but not used by employees during necropsy procedures. According to employees, N95 filtering facepiece respirators were 
used if a suspected zoonotic disease hazard was identified by the necropsy team during the procedure. Employees who conducted necropsy procedures had not been fit tested and were not included in the respiratory protection program.

During one of the necropsies we observed, guest researchers from a local university collected a sea lion brain. A bone saw was used to open the skull, which generated visible tissue and bone-related aerosols. The team wore surgical masks, short-sleeved scrubs, aprons, rubber boots, and powder-free latex gloves. Headquarters employees observed this procedure in the necropsy room while wearing similar PPE. Neither the university team nor the headquarters employees wore respiratory protection during this procedure. Water sprayed from a hose was used to wash away blood during the necropsy. This practice could generate aerosols in the work area.

After the necropsies, carcasses were loaded into drums for offsite disposal. The drums were placed on the floor next to the necropsy table, and carcasses were pushed from the table into the drums, creating a spray of blood. After gross blood contamination was washed down the drains with water, the necropsy room was scrubbed with a $10 \%$ household bleach solution and dishwashing detergent.

\section{Laboratory}

The headquarters facility had a clinical and microbiology laboratory in adjacent rooms that was staffed by four employees and four volunteers. The laboratory had clinical diagnostic and research capabilities. Several pieces of equipment processed clinical (blood, urine, fecal) specimens. The laboratory was served by two BSCs. The clinical laboratory had a Class II B2 cabinet that was exhausted to the outside and was used for formalin fixing and bagging tissue samples. The microbiology laboratory had a Class II A2 cabinet used for plating culture samples. This cabinet recirculated air back into the room after passing through a highefficiency particulate air filter. The microbiology laboratory also had a cabinet that was used to store formalin-fixed tissue samples. This cabinet was fitted with mechanical ventilation and was exhausted to the outside. Other laboratory processes including hematology, blood smears, and blood chemistry were processed outside the BSCs. In the microbiology laboratory, culture plates were opened and counted on an open bench top (not in the BSC). Further manipulation of the culture plates and any other aerosol generating activities were done in the BSC. During laboratory procedures, we observed employees wearing powderfree natural latex gloves and, in some cases, lab coats.

\section{Ventilation Assessment}

Table 3 summarizes the air velocity measurements and results of smoke tube testing on the BSCs. The average face velocity was 113 feet per minute (fpm) for the clinical laboratory BSC and $92 \mathrm{fpm}$ for the microbiology laboratory BSC. Both BSCs demonstrated effective capture of smoke at the hood face. The testing and certification tag on the BSC in the clinical laboratory indicated that recertification had been due in November 2009. The testing and certification tag on the BSC in the microbiology laboratory indicated that the BSC was up to 
Table 3. Evaluation of the biological safety cabinets at the headquarters laboratory*

\begin{tabular}{lccc}
\hline Location & Area of face $\left(\mathrm{ft}^{2}\right)$ & \multicolumn{2}{c}{ Air velocity $(\mathrm{fpm})$} \\
& & Range & Mean \\
\hline $\begin{array}{l}\text { Clinical laboratory } \\
\text { BSC }\end{array}$ & 1.9 & $85-146$ & 113 \\
$\begin{array}{l}\text { Microbiology } \\
\text { laboratory BSC }\end{array}$ & 2.3 & $36-144$ & 92 \\
\hline
\end{tabular}

${ }^{*}$ Air velocity and smoke tube measurements were taken at the face of the BSCs.

date, and that recertification was due in June 2012.

The fixed tissue storage cabinet had two relief vents at the bottom of the cabinet doors to provide airflow through the cabinet and prevent buildup of formaldehyde vapors. Smoke tube testing revealed that minimal airflow was entering the cabinet. Tissue samples stored inside were blocking the relief vents.

The harbor seal area was served by a multi-zone, variable air volume air handling unit that recirculated return air from all areas in the building and mixed it with outdoor air. (The percent outdoor air unknown). The ventilation system was used approximately 10 days per year when additional heating or cooling was required. Typically, the building was naturally ventilated by open windows and doors. When the ventilation system was running, air flowed from the harbor seal ICU to the adjacent hallway leading to other areas within the building. When the ventilation system was turned off, air movement between the harbor seal ICU and the adjacent hallway was neutral.

\section{Environmental Sampling}

All 37 general area and personal breathing zone air samples were negative for C. burnetii. We collected 69 surface wipe samples and 10 bulk dust samples; one collected on a light fixture in the headquarters topside fish kitchen was positive for $C$. burnetii. All other surface samples and bulk dust samples were negative for $C$. burnetii.

\section{Discussion}

Our serologic evaluation revealed little evidence of past infection of employees and volunteers with leptospirosis, brucellosis, or Q fever. The two participants with titers that met the case definition for evidence of past infection with leptospirosis had worked at the center for at most 2 months, and had other exposures associated with leptospirosis infection, which makes infection from sources outside the facility more likely.

Brucellosis titer interpretation and evidence of past infection is complicated because a titer of $\geq 1: 160$, compatible clinical symptoms, and probable exposure are typically used to diagnosis 
a clinical case of brucellosis.

C. burnetti seroprevalence was found to be $4 \%$ among those we tested, and this is comparable to the $3 \%$ seroprevalence estimated for the general U.S. adult population [Anderson et al. 2009]. In our analysis, we found that characteristics significantly associated with prior exposure to $C$. burnetii included ingestion of raw, unpasteurized dairy products in the past year, contact with feral swine blood and/or fluids in the past year, and a veterinary occupation. None of these risk factors necessarily implicate marine mammals or marine mammal rescue work, as they may be unrelated to marine mammals. Raw milk from infected cows contains organisms and may serve as a transmission route to humans [Heymann 2004], and a veterinary occupation is a well-recognized risk factor for $C$. burnetii seropositivity. Studies of U.S. veterinarians estimate a $22 \%$ seroprevalence for $C$. burnetii [Whitney et al. 2009a]. Little is known about the virulence of marine mammal C. burnetii strains in humans. However, case reports have associated human infections with a variety of other bacterial, viral, and parasitic zoonotic agents in people with occupational exposure to marine mammals in field and laboratory settings [Hunt et al. 2008].

Our environmental sampling results suggest a very low environmental load of C. burnetii at both facilities at the time of our evaluation. C. burnetii in its spore like form is highly resistant to desiccation, and can survive for extended periods in the environment [van Woerden et al. 2004]. We sampled in infrequently cleaned areas and collected dust from vacuum cleaner bags to maximize our chances of detecting $C$. burnetii, yet we detected $C$. burnetii in only one sample. Either $\mathrm{Q}$ fever infections are uncommon in the marine mammal population served by the facilities or cleaning methods are effectively controlling C. burnetti contamination. However, in a recent study, C. burnetii seropositivity was detected in $34 \%$ of 215 Pacific harbor seals sampled in the Pacific Northwest [Kersh et al. 2012]. For C. burnetii, infection is most commonly associated with dry and dusty environments, as these conditions are more amenable to the bacterium becoming airborne and increasing the likelihood that the bacterium is spread to areas away from the source of contamination (i.e. the marine mammal). The marine environment, specifically the one in this evaluation, is neither dry nor dusty, and it is regularly cleaned. This may limit the potential for the bacterium to be transmitted to humans and surfaces.

Though the serologic survey revealed little evidence of past infection with the three zoonotic agents, we did observe work practices that could increase risk for exposure and infection with zoonotic agents. The NASPHV has guidelines for standard precautions for zoonotic disease prevention in veterinary personnel [NASPHV 2010]. The guidelines include infection control measures, PPE for specific types of tasks (including animal handling and necropsy), and other information. These guidelines are appropriate for the center's veterinary personnel, other employees, and volunteers with potential exposure to zoonotic agents.

In the pen areas at the headquarters facility and triage facility, volunteers and employees wore appropriate PPE, demonstrated good cleaning techniques of pens, and used foot baths frequently when walking around the pen areas. However, some volunteers at the headquarters facility reported not washing their hands after handing animals because they had been 
wearing gloves. These anecdotal reports were supported by our survey results, which revealed that $9 \%$ of participants who reported caring for marine mammals reported that they did not always wash their hands before eating. NASPHV states that the use of gloves is not a substitute for hand washing because gloves can have undetected tears. Additionally, hands can become contaminated when removing gloves.

At the triage facility, we observed that volunteers and employees wore street shoes while working with animals and cleaning cages and pens. Though employees and volunteers used foot baths to decontaminate their street shoes, shoes with porous materials (such as gym shoes or leather boots) are difficult to fully decontaminate. Rubber boots were also reportedly available at the triage facility and were used if significant wet work was anticipated.

At both facilities, we either observed or were told by volunteers that PPE was worn in chart rooms or other areas where individuals ate or drank. Additionally, the triage facility was carpeted in most indoor areas. Because carpeting is a porous surface, it is difficult to properly clean and sanitize.

Our survey results showed that $95 \%$ of 211 participants caring for marine mammals reported wearing gloves at least most of the time during their work at the facility, which suggests good compliance with this practice. We observed that employees and volunteers mostly used powder-free natural rubber latex gloves at both facilities. Though latex gloves do provide an effective barrier against infectious agents, other glove materials including nitrile or vinyl are acceptable alternatives that can be used to minimize the potential for latex allergy [NASPHV 2010]. NIOSH provides guidance on the potential hazards and recommendations on the use of natural latex gloves [NIOSH 1998].

The potential for exposure to infectious agents could be present when transporting animals from the beach via an enclosed van because the health status of these animals has not been fully evaluated. Using a pickup truck whenever possible may better protect staff from exposures to airborne infectious agents such as C. burnetti and Brucella spp.

Our survey results showed that 77 participants reported ever having contact with dead marine mammal tissues, fluids, and blood during necropsies. These 77 participants included 49 volunteers, 26 paid employees, and two participants who reported both. A majority of these participants reported they never wore gloves, masks, or respirators during their work. During the necropsies we observed at the main facility, we did not see volunteer participation. Also, managers told us that volunteers typically did not participate in necropsies at the facility, as they were performed by paid staff or guest researchers. It is possible that more volunteers reported being present at necropsies than expected because they may have participated in necropsies or tissue collection on the beach or at locations other than the main facility. In the necropsy area of the main facility, we observed that PPE for droplet exposure (such as a face shield, or goggles and face mask) was not worn by employees during necropsies, cleanup after the necropsies, or transfer of animal carcasses into drums. In addition, we observed the use of a bone saw to facilitate brain collection, which generated visible aerosols from tissue 
and bone; however, respiratory protection was not worn by those in the room. Employees reported that respiratory protection was only worn if a possible inhalation exposure hazard was recognized during a necropsy and that this occurred very rarely. At the time of our evaluation, employees working in the necropsy area were not included the respiratory protection program. NASPHV and CDC provide recommendations for the type of PPE that should be worn during animal necropsies if there is a high likelihood of exposure to zoonotic agents [NASPHV 2010; CDC 2012a].

In the laboratory, risk of exposures to biological agents appeared to be generally low. The lab functioned as a BSL 2 laboratory though CDC categorizes both C. burnetii and Brucella spp. as Group 3 risk agents that might be present in a veterinary diagnostic laboratory. The facility's director of veterinary science reported that no cases of Q fever or brucellosis infections had been diagnosed among animals housed at the facility. If these agents are encountered in laboratory specimens, CDC recommends manipulating them using BSL 3 work practices and equipment because these agents can cause serious infections as a result of inhalation exposure [CDC 2012a]. Leptospira spp. is classified as a Group 2 agent and is recommended to be handled under less rigorous BSL 2 work practices and equipment [CDC 2012a].

The "Biosafety in Microbiological and Biomedical Laboratories, 5th edition" document provides information on the use of BSCs in the laboratory environment [DHHS 2009]. For Class II A2 and B2 BSCs, this document recommends that average air velocity across the face of a BSC be at least $100 \mathrm{fpm}$. The average air velocity that we measured at the BSC in the clinical laboratory $(113 \mathrm{fpm})$ met this recommendation. However, the BSC in the microbiology laboratory had an average face velocity slightly below this recommendation (92 fpm), and in one location the velocity was only $36 \mathrm{fpm}$. The clinical laboratory BSC had not been certified since 2009, placing it out of the certification period recommended by this document and by the contractor that serviced the BSC at the facility. Relief vents on the formalin fixed tissue cabinet were blocked and could prevent proper exhaust of formaldehyde vapors, leading to increased exposures among laboratory staff.

The ventilation system in the harbor seal area was rarely used. However, when it was turned on, it directed air from the harbor seal pup area to other areas of the building where the air was recirculated, which could potentially spread zoonotic agents. Even with this ventilation system turned off, natural ventilation could spread infectious agents throughout the building. Housing animals in outdoor pens whenever possible is the best option.

C. burnetii is very resistant to heat, drying, and most common disinfectants. Scott and Williams [2006] found that aqueous solutions containing C. burnetii in concentrations of $10^{8}$ organisms were not completely inactivated by $0.5 \%$ hypochlorite, $5 \%$ Lysol ${ }^{\circ}, 5 \%$ formalin, or $2 \%$ Roccal ${ }^{\circledR}$ after 24 hours at 24 degrees Celsius. However, C. burnetii was completely inactivated within 30 minutes by either $70 \%$ ethanol, $5 \%$ chloroform, or 5\% Enviro-ChemTM. Both Leptospira spp. and Brucella spp. are more susceptible to common disinfectants. Liquid antimicrobial products that can inactivate Leptospira spp. include a 1\% bleach solution, iodine-based disinfectants, accelerated hydrogen peroxide, and quaternary ammonium compounds [Sykes et al. 2010]. For Brucella spp., $\mathrm{pH}$ amended bleach (mixture 
of 1 part household bleach [5.25\% to $6.0 \%$ ] to 1 part white vinegar to 8 parts water) is recommended [NRT 2011]. Further guidance on the use of pH amended bleach for Brucella spp. can be found in the National Response Team Quick Reference Guide for Brucella spp. at http://www.nrt.org/Production/NRT/NRTWeb.nsf/AllAttachmentsByTitle/A-1009WMDQRG BrucellaSpecies/\$File/120502 Brucella_QRG Final.pdf?OpenElement. We understood that the facility used a $10 \%$ bleach solution made from calcium hypochlorite. This concentration will inactivate both Leptospira spp. and Brucella spp. but it is unclear if it will inactivate C. burnetii. Consideration should be given to the use of other recommended disinfectants if veterinary staff strongly suspects that a marine mammal may be infected with $\mathrm{Q}$ fever. This may be especially important in areas where there may be greater exposure to C. burnetii containing blood and body fluids, such as surgical, necropsy, and laboratory settings, and when handling placental tissues or neonatal pups.

Our evaluation was subject to some limitations. First, most of our participants were based at the headquarters facility. We were not able to include all employees and volunteers at the other satellite facilities and the stranding network. Therefore, our serologic survey results may not be generalizable to all employees and volunteers exposed to marine mammals. Second, serologic testing for Q fever and leptospirosis indicates if one has been infected at some point in the past, but these tests are unable to determine when infection occurred. It is also possible that antibody titers may wane over time, leading to false negative serologic results for remote infections. Third, because of limitations in laboratory capabilities, our environmental sampling was restricted to $C$. burnetii, and we were unable to determine environmental contamination with Brucella spp. and Leptospira spp. Finally, contact with infected birth products is thought to be a mode of transmission of $C$. burnetii, and harbor seals in this region of California typically give birth from February to April. Because our evaluation took place in late June, we may have been less likely to detect environmental contamination with $C$. burnetii because of the low numbers of harbor seals at the facility.

\section{Conclusions}

Our evaluation found little evidence of past infection on the basis of antibody titers for employees and volunteers exposed to marine mammals, suggesting a low occupational exposure to Q fever, leptospirosis, and brucellosis among this population. In addition, our environmental sampling suggests a very low environmental load of $C$. burnetti at both facilities at the time of our evaluation. However, prior studies have shown that marine mammals can have clinical illness or antibodies against the organisms that cause Q fever, brucellosis, leptospirosis, and other zoonotic infections, which may be transmitted to employees and volunteers caring for them. The fact that some participants had Brucella titers indicating possible past infection and the finding of positive Q fever titers among some participants indicate that infection could have occurred while working with marine mammals at this or other facilities. Because leptospirosis is seen in animals routinely treated at this facility, precautions as discussed in our recommendations are important to protect worker health. Inappropriate work practices, insufficient PPE use, and engineering control deficiencies suggest that employees and volunteers were at risk for acquiring zoonotic infections.

Health Hazard Evaluation Report 2011-0105-3173 


\section{Recommendations}

On the basis of our findings, we recommend the actions listed below. We encourage marine mammal rescue and rehabilitation facility to use a labor-management health and safety committee or working group to discuss our recommendations and develop an action plan. Those involved in the work can best set priorities and assess the feasibility of our recommendations for the specific situation at marine mammal rescue and rehabilitation facility.

Our recommendations are based on an approach known as the hierarchy of controls. This approach groups actions by their likely effectiveness in reducing or removing hazards. In most cases, the preferred approach is to eliminate hazardous materials or processes and install engineering controls to reduce exposure or shield employees. Until such controls are in place, or if they are not effective or feasible, administrative measures and personal protective equipment may be needed.

\section{Engineering Controls}

Engineering controls reduce employees' exposures by removing the hazard from the process or by placing a barrier between the hazard and the employee. Engineering controls protect employees effectively without placing primary responsibility of implementation on the employee.

1. Recertify the BSC in the clinical laboratory. $\mathrm{CDC}$ recommends annual recertification [CDC 2012a].

2. Recertify the microbiology laboratory BSC to ensure minimum airflow of $100 \mathrm{fpm}$ across the face of the cabinet [DHHS 2009; CDC 2012a].

3. Rearrange items in the formalin laboratory storage cabinet to ensure that airflow through the relief vents is not blocked by items stored in the cabinet. Use visual smoke or another test, such as using a small piece of facial tissue ("tissue test"), to determine if air is moving into the cabinet. Evaluate this storage cabinet as part of the annual ventilation recertification process.

4. Do not house harbor seal pups in the harbor seal ICU if Q fever infection is suspected. Develop a long-term solution that provides housing for these animals in an area that does not share ventilation with the harbor seal building. In the interim, do not use the ventilation system in the harbor seal area building when housing animals suspected of having Q fever within the harbor seal ICU. Air from this area is distributed to other areas of the harbor seal building. Also, keep the door between the harbor seal ICU and adjacent hallway closed when animals are housed in this area. 


\section{Administrative Controls}

The term administrative controls refers to employer-dictated work practices and policies to reduce or prevent hazardous exposures. Their effectiveness depends on employer commitment and employee acceptance. Regular monitoring and reinforcement are necessary to ensure that policies and procedures are followed consistently.

1. Provide initial and semiannual refresher training on hand washing for all volunteers and employees. Include guidance about the importance of hand washing after the removal of gloves because contamination can occur even with glove use. Post additional signage about hand washing at all facilities.

2. Prohibit eating and drinking in the chart room and other areas where PPE is worn.

3. Develop a written policy and educate employees and volunteers to remove PPE before entering the triage facility (other than the fish kitchen and garage area) as this could spread contamination from animals throughout the building. Other triage facilities should follow this same recommendation.

4. Restrict the number of people involved in necropsies to the minimum number necessary to complete the procedure to limit potential exposure to zoonotic agents.

5. Remove the carpeting in the triage facility and replace it with nonporous flooring material that can be more easily cleaned.

6. Develop additional training for new and current employees and volunteers about the signs and symptoms of common zoonotic infections and steps they can take to minimize their risk of infection. Employees and volunteers with conditions such as pregnancy, valvular heart disease, or immunodeficiency that put them at risk for severe infection from certain zoonotic agents such as Q fever should share this information with their supervisor.

7. Instruct employees and volunteers who develop signs and symptoms compatible with a zoonotic infection to inform their supervisor and seek medical care. They should tell their healthcare provider about their duties and exposure to marine mammals.

8. Update the respiratory protection program following the OSHA Respiratory Protection Standard regulations [29 CFR 1910.134] to include employees and volunteers working in the necropsy area. Additionally, develop a policy for ensuring guest researchers are enrolled in their organization's respiratory protection program and use appropriate PPE during aerosol-generating procedures (such as bone sawing during necropsy).

\section{Personal Protective Equipment}

Personal protective equipment is the least effective means for controlling hazardous exposures. Proper use of personal protective equipment requires a comprehensive program and a high level of employee involvement and commitment. The right personal protective equipment must be chosen for each hazard. Supporting programs such as training, changeout schedules, and medical assessment may be needed. Personal protective equipment 
should not be the sole method for controlling hazardous exposures. Rather, personal protective equipment should be used until effective engineering and administrative controls are in place.

1. Follow NAPSHV and CDC recommendations for PPE use during necropsy procedures [NASPHV 2010; CDC 2012a]. These include routinely wearing facial protection (face shield, or goggles and a surgical mask), fluid resistant (surgical) jumpsuit or shirt and pants that cover from neck to feet and arms, waterproof apron, and waterproof sleeves. Wear double gloves during necropsy. Wear N95 filtering facepiece (or higher) respirators during aerosol-generating procedures (such as during the use of bone saws or high pressure water hoses). For necropsies in which a risk assessment indicates a high likelihood for zoonotic agents in the cadaver and the necropsy cannot be conducted in a BSC, an N95 filtering facepiece (or higher) respirator should also be worn [CDC 2012a]. Offer alternatives, such as nitrile or vinyl, to powder-free natural rubber latex to reduce the risk of latex allergies.

2. Wear rubber boots rather than street shoes when working around animal pens at the triage facility.

3. Instruct maintenance staff to wear N95 filtering facepiece (or higher) respiratory protection during filtration room cleaning tasks.

4. Require laboratory staff to wear lab coats during all procedures in the laboratory. These coats should only be worn in the lab and laundered on-site or by a management provided laundry service. 


\section{Appendix A: Background Information on Zoonotic Infections}

\section{Q Fever}

Q fever is a zoonotic disease caused by the globally distributed bacterium Coxiella burnetii. There are two forms of disease, acute and chronic. Infected people develop clinical symptoms approximately half of the time. The most commonly recognized forms of acute disease are a nonspecific flulike illness, pneumonia, and hepatitis. Most people with acute $\mathrm{Q}$ fever infection recover completely, but a protracted fatigue syndrome has been reported in a minority of patients with acute infections. Chronic $\mathrm{Q}$ fever is rare and most commonly presents as endocarditis in those with pre-existing valvular heart disease. Pregnant women, immunosuppressed persons, and patients with pre-existing heart valve defects are at highest risk for chronic $\mathrm{Q}$ fever.

Humans are typically exposed to the $C$. burnetii organism through contact with birth products (amniotic fluid and placenta), urine, or feces of infected animals. Ruminants (e.g., goats, sheep, and cattle) are considered the primary C. burnetii reservoir, but other species such as feral swine have been associated with human infections. C. burnetii is a highly infectious bacterium and exposure to only a few organisms can lead to infection. The organism can withstand a variety of environmental conditions. Transmission typically occurs via inhalation of contaminated aerosols or dust, but $C$. burnetii can rarely be transmitted by tick bites or ingestion of unpasteurized dairy products. Aerosols may be generated from infected animals, placental tissues and fluids, waste products, and contaminated straw or bedding [van Woerden et al. 2004].

Human exposure to marine mammals may be a potential risk factor for $\mathrm{Q}$ fever infection, but rates of infection among people working with marine mammals have not been previously investigated. C. burnetii infection in a marine mammal was first confirmed in the placental tissue of a rescued Pacific harbor seal in California [Lapointe et al. 1999]. Subsequent investigations have found evidence of $C$. burnetii infection in the Steller sea lion [Kersh et al. 2010], as well as in the Pacific harbor seal, harbor porpoise, and Northern fur seal [Lapointe et al. 1999; Duncan et al. 2012; Kersh et al. 2012]. A recent study did find C. burnetii seropositivity was detected in $34 \%$ of 215 Pacific harbor seals sampled in the Pacific Northwest [Kersh et al. 2012]. The significance of these new findings and the relationship to human $\mathrm{Q}$ fever infection is poorly understood. Recently, a patient with Q fever endocarditis was reported in Greenland with harbor or hooded seals implicated as a possible source of infection [Koch et al. 2010].

\section{Brucellosis}

Human brucellosis occurs worldwide and is most often associated with close contact with cattle, sheep, goats, and other hoofed mammals. The disease is caused by infection with bacterial species from the genus Brucella. The most commonly reported species infecting humans (and their typical reservoirs) include B. melitensis (sheep and goats), B. abortus 
(cattle), B. suis (swine), and B. canis (dogs). Humans are generally infected in one of three ways: eating or drinking something that is contaminated with Brucella spp. (e.g., unpasteurized milk or cheese), breathing in the organism (inhalation), or having the bacteria enter the body through skin wounds [CDC 2012b]. Inhalation of Brucella organisms is not a common route of infection, but it can be a significant hazard for people in certain occupations, such as those working in laboratories where the organism is cultured or in abattoirs [Trout et al. 1995].

Human brucellosis is rarely fatal, but symptoms can be severe. Acute symptoms may include nonspecific flulike illness, arthritis and, rarely, neurological disorders and endocarditis. Brucellosis can become a chronic condition in some patients, with symptoms such as depression, arthritis, or chronic fatigue syndrome.

Brucella spp. infects a variety of marine mammals, including species of dolphin, porpoise, whale, seal, otter, and walrus [Ewalt et al. 1994; Ross et al. 1994]. To date, molecular analyses have linked marine mammal Brucella spp. to three naturally acquired, severe human illnesses [Sohn et al. 2003; McDonald et al. 2006] and one laboratory acquired illness [Brew et al. 1999]. Prevalence of Brucella spp. infections from marine mammal reservoirs is thought to be much higher than reports indicate, especially among those working with marine mammals [Hunt et al. 2008] and those in the fishing industry [Van Bressem et al. 2009] due to frequent misdiagnoses and underreporting.

\section{Leptospirosis}

Leptospirosis is a potentially fatal bacterial disease caused by Leptospira spp. It may present as an acute, nonspecific flulike illness (e.g., fever, headache, muscle pain, diarrhea) or as a more severe chronic illness with symptoms such as liver or kidney failure, meningitis, or pulmonary hemorrhage.

Leptospira spp. are spread through the urine of many wild and domestic animals (e.g., cattle, swine, rodents, dogs, sheep, and raccoons). Infection may result from direct contact with animal urine or from exposure to contaminated soil or water. Leptospirosis is also a recreational hazard (e.g., swimming, wading, paddling), an occupational hazard (e.g., slaughterhouse workers, veterinarians, farmers, sewer workers), and is associated with flooding.

The most common exposure routes for development of leptospirosis include (1) drinking or contact with water (such as by swimming, rafting or kayaking) or soil that has been contaminated by urine or body fluids of infected animals or (2) exposure to the urine or body fluids of infected animals. The bacteria can enter the body through skin or mucous membranes (eyes, nose, or mouth), especially if the skin is broken from a cut or scratch [CDC 2012c]. 
Known marine mammal reservoirs of Leptospira spp. include fur seals [Smith et al. 1977], elephant seals [Colegrove et al. 2005], and harbor seals [Stamper et al. 1998]. Repeated outbreaks of leptospirosis have occurred in California sea lion populations from southern California to British Columbia. The outbreaks have killed large numbers of sea lions [LloydSmith et al. 2007]. These animals typically died after being stranded in regions with dense populations of other known Leptospira hosts (i.e., rodents, domestic animals, and other marine mammals), suggesting the potential for interspecies transmission, from marine mammals to humans directly or, possibly, through an intermediate species. Leptospira excreted by sea lions has also been detected in sand [Cameron et al. 2008]. 


\section{Appendix B: Informational Fact Sheets and Website Link Distributed to Employees and Volunteers}

These informational fact sheets and websites were provided to facility employees and volunteers during the evaluation.

Facts about brucellosis: http://www.cdc.gov/brucellosis/

\section{Facts about Q Fever for Marine Mammal Workers}
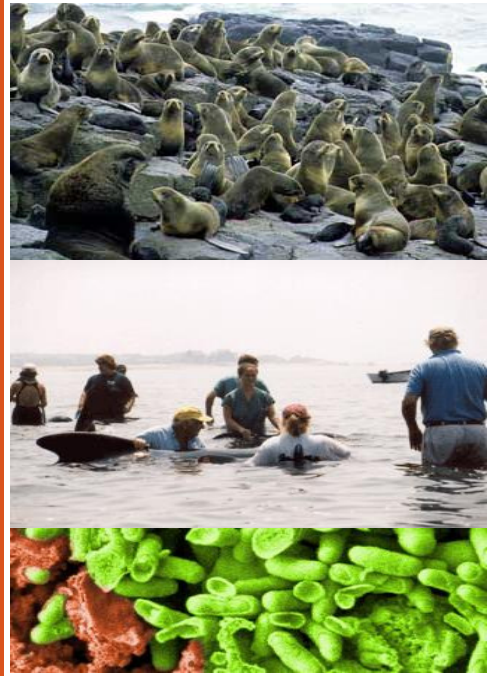

Electron micrograph of Coxiella burnetii

\section{What is $\mathbf{Q}$ fever?}

Q fever is a disease caused by Coxiella burnetii, a species of bacteria that can infect humans and many other animal species. Q fever is commonly found throughout the world and cases have been reported throughout the U.S.

\section{What causes $\mathbf{Q}$ fever?}

Humans are typically exposed to Coxiella through close contact with infected animals or their birth products (placentas, fetuses, amniotic fluid), urine, feces, or milk. People can become infected by breathing in contaminated dust or aerosols. Rarely, people can also become infected from a tick bite, ingesting contaminated milk, or during close contact with an infected person. Transmission to humans may also occur after contact with contaminated clothing and linens. The $\mathrm{Q}$ fever bacterium is extremely hardy; it can survive in the environment for long periods of time and become airborne, traveling on wind currents for miles.
What are the symptoms of Q fever?

Only about half of the people infected will get sick with $\mathrm{Q}$ fever. Symptoms usually begin 2 to 3 weeks after exposure, and include fever, headache, chest or stomach pain, muscle aches, weight loss, chills or cough. The fever can last 1 to 2 weeks, but some people can also get serious lung or liver infections. Most people recover within 1 to 2 months of infection. Rarely, chronic symptoms can develop, such as endocarditis, recurrent miscarriages, chronic granulomatous infections, or long-term fatigue. People with weak immune systems, pregnant women, and people with heart valve defects are at high risk for chronic $Q$ fever.

\section{Which animals can be} infected?

Many animal species can be infected including livestock (such as cattle, sheep, and goats), dogs, wild mammals, birds, fish, reptiles, and ticks. Coxiella has also been found in marine mammals (such as sea lions, seals, and whales). Although most infected animals may not look ill, they may still be shedding Coxiella.

\section{Can humans get $\mathbf{Q}$ fever from marine mammals infected with Coxiella} burnetii?

To date, there have been no human cases of $Q$ fever linked to marine

mammal exposure. The different Coxiella strains that are present in animal species may vary in their ability to infect people. Additionally, animals may respond differently to Coxiella infection, which influences the signs of illness, length of shedding, and the overall disease risk to people. There are also environmental factors that influence the risk of human transmission, such as animal density local reservoirs, tick vectors, species diversity, and amount of human-animal contact. Marine mammals have not been studied yet to understand how they respond to $Q$ fever infection and what role, if any, they play in spreading infection to people.
How can I prevent $Q$ fever infection?

Clothing and boots worn in rookeries, or areas where animals have recently birthed, should be removed and washed or disinfected before returning home or entering the house. Hands and arms should be washed thoroughly after animal contact. Those at high risk for chronic $\mathrm{Q}$ fever (pregnant women, persons with weak immune systems, or persons with heart valve defects) should avoid areas where animals have recently given birth. Only pasteurized dairy products should be used.

How is $\mathbf{Q}$ fever diagnosed? Current or past $\mathrm{Q}$ fever is diagnosed by blood tests. While people are ill, evidence of Coxiella infection may be detected in their blood. Additionally, Coxiella antibodies may be detected in blood from people or animals who are not currently ill but were exposed to Coxiella at some point in the past.

\section{How is $Q$ fever treated?}

An acute case of $Q$ fever is treated with the antibiotic doxycycline for 2 weeks. The earlier doxycycline is started, the more effective it is in treating the infection. Other antibiotics may be prescribed for those unable to take doxycycline.

If I think I have $Q$ fever, what should I do?

If you feel unwell and have symptoms consistent with $\mathrm{Q}$ fever, you should seek medical care. $Q$ fever is diagnosed with a blood test, but treatment should begin immediately if $Q$ fever is suspected, even while laboratory tests are pending.

\section{Who should I contact for} more information?

For more information, please visit CDC's website on Q fever at

http://www.bt.cdc.gov/agent/qfever or http://www.cdc.gov/qfever/. If you think you may be ill with $Q$ fever, you should contact your health care provider. 


\section{Leptospirosis \\ Leptospirosis is an infectious disease caused by bacteria. It can lead to potentially fatal infections of the kidney, liver, brain, lung or heart.}

\section{How do people get Leptospirosis?}

There are two common ways to develop leptospirosis:

- Drinking or contact with water (such as by swimming, rafting or kayaking) or soil that has been contaminated by urine or body fluids of infected animals

- Exposure to the urine or body fluids of infected animals

\section{What are the symptoms of leptospirosis?}

Symptoms of leptospirosis can develop anywhere from 2 days to 4 weeks after being exposed to the bacteria.

Common symptoms of leptospirosis include:

- Fever

- Chills

- Headache

- Muscle Aches

- Vomiting

- Diarrhea

- Abdominal Pain

- Jaundice (yellowing of the skin and eyes)

- Skin Rash

- Red Eyes

Which animals can spread leptospirosis to people? Many animals can spread leptospirosis, including pets (such as dogs), farm animals, or wildlife.

The animals that commonly develop or spread leptospirosis include:

- Rodents

- Raccoons

- Opossums

- Cattle

- Swine

- Dogs

- Horses

- Buffaloes

- Sheep

- Goats

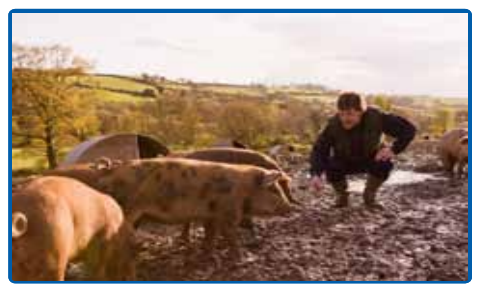

\section{Am I at risk?}

There is always a risk of infection for people who have contact with infected animals or soil/water where the bacteria are present People who work outdoors or with animals may be at increased risk for infection, such as:

- Farmers

- Mine Workers

- Sewer Workers

- Slaughterhouse Workers

- Veterinarians/Animal Caretakers

- Fishermen and people who work with fish

- Dairy Farmers

- Military Personnel

Those involved in outdoor freshwater activities may also face an increased risk. Activities may include:

- Swimming

- Rafting

- Kayaking

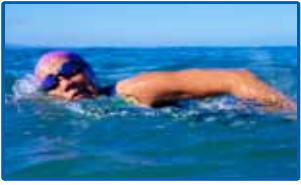

How is Leptospirosis treated?

If you have symptoms of leptospirosis, contact a doctor who can test for the disease.

If an infection is confirmed, it will likely be treated with antibiotics (medicine that can cure the disease). Treatment is most effective when started as soon as possible.

\section{How can Leptospirosis be prevented?}

There are several steps you can take to help prevent getting leptospirosis. These include:

- See a veterinarian to get vaccines for your pets that can protect against this disease

- Avoid contact with animal urine or body fluids, especially if there are any cuts or abrasion of the skin

- Do not swim in, walk in, or swallow water that may contain animal urine

- Wear protective clothing or footwear near soil or water that may be contaminated with animal urine

For More Information Contact CDC Info:

1-800-CDC-INFO (1-800-262-4636)/TTY 1-888-232-6348

or visit our website at www.cdc.gov/leptospirosis 


\section{Appendix C: Methods}

\section{Serologic Samples}

NIOSH phlebotomists collected 10 milliliters of whole blood from each participant into a serum separation tube. The tubes were centrifuged and transported on ice by overnight courier to CDC in Atlanta, Georgia. For Q fever testing, the specimens were screened by an ELISA for IgG antibodies against phase II C. burnetii. If positive, or equivocal, they were tested by IFA assay to confirm the ELISA results and to determine IgG and IgM titers against phase I and phase II C. burnetii antigens. Coxiella testing was conducted the laboratory within CDC's Rickettsial Zoonoses Branch. For brucellosis testing, sera were tested by the Brucella MAT, as previously described [Brown et al. 1981] with minor modifications including use of U-bottom plates, incubation at $28^{\circ} \mathrm{C}$, and discontinued use of safranin. The Leptospira MAT [Dikken and Kmety 1978; Levett 2001] was used for leptospirosis testing of 20 serovars. Brucellosis and leptospirosis testing was conducted by the laboratory within CDC's Bacterial Special Pathogens Branch.

\section{Surface Samples}

Solar-cult ${ }^{\circledR}$ cellulose sponges, premoistened with neutralizing buffer (Solar Biologics, Ogdensburg, New York) were used to collect samples on smooth, nonporous surfaces.

Multiple surfaces in each area were wiped with a sponge to maximize potential recovery of C. burnetii from the environment. In a few cases, two sponge samples were combined into a composite sample because of the large size of the area. A new pair of disposable nitrile gloves was used for collection of each sample to prevent cross contamination of samples. Field blanks were collected at a rate of $10 \%$ of actual samples collected.

Vacuum samples were collected on 37-millimeter diameter, 0.3-micrometer pore size polytetrafluoroethylene filters with small nozzle attachments connected to battery-powered sampling pumps at 2 liters per minute. Porous surfaces, such as carpeted mats, were vacuumed over an area measured in $\mathrm{cm} 2$ using three sets of S-curve wipes over the surface. A new pair of disposable nitrile gloves was used for collection of each sample to prevent cross contamination of samples. Field blanks were collected at a rate of $10 \%$ of actual samples collected.

\section{Bulk Samples}

Approximately 10 to 50 grams of dirt or debris was collected and placed into sterile conical vials. A new pair of disposable nitrile gloves was used for collection of each sample to prevent cross contamination of samples. Field blanks were collected at a rate of $10 \%$ of actual samples collected.

\section{Air Samples}

Personal breathing zone and area air samples were collected on 37-millimeter diameter, 0.3 -micrometer pore size polytetrafluoroethylene filters. The filter cassettes were connected to battery-powered SKC AirChek 2000 sampling pumps (SKC Incorporated, Eighty Four, 
Pennsylvania) and operated at 3 liters per minute. All pumps were precalibrated and postcalibrated with the sampling media connected. The collection and extraction efficiencies of this filter for another bacterial agent have been previously described by Burton et al. $[2005,2006]$. Field blanks were collected at a rate of $10 \%$ of actual samples collected.

\section{Sample Storage, Shipment, and Analysis}

After collection, all samples were placed in plastic storage bags and stored and shipped at room temperature. Samples were shipped to the CDC Rickettsial Zoonoses Branch in Atlanta, Georgia, and analyzed for DNA extraction and quantitative PCR to determine if C. burnetii DNA was present. Methodology for this PCR assay has been previously described [Fitzpatrick et al. 2010]. The limit of detection for the PCR assay is 500 organisms per 5 grams bulk environmental/sponge/37-mm filter sample. All DNA samples were analyzed by quantitative PCR targeting two C. burnetii genes. The IS1111 assay targets a variable number multi-copy gene segment and is therefore very sensitive. The com1 assay targets a single copy gene. For most strains of $C$. burnetii, the com 1 assay is less sensitive than IS1111. However, some $C$. burnetii strains found in marine mammals have an altered IS1111 gene that is poorly amplified by this assay. Therefore, a stronger signal from the com1 PCR compared to the IS1111 PCR would be indicative of a marine mammal derived strain. 


\section{References}

Anderson AD, Kruszon-Moran D, Loftis AD, McQuillan G, Nicholson WL, Priestley RA, Candee AJ, Patterson NE, Massung RF [2009]. Seroprevalence of Q fever in the United States, 2003-2004. Am J Trop Med Hyg 81(4):691-694.

Brew SD, Perrett LL, Stack JA, MacMillan AP, Staunton NJ [1999]. Human exposure to Brucella recovered from a sea mammal. Vet Rec 144(17):483.

Brown SL, Klein GC, McKinney FT, Jones WL [1981]. Safranin O-stained antigen microagglutination test for detection of brucella antibodies. J Clin Microbiol 13(2):398400.

Burton NC, Adihari A, Grinshpun SA, Horning R, Reponen T [2005]. The effect of filter material on bioaerosol collection of Bacillus subtilis spores used as a Bacillus anthracis simulant. J Environ Monit 7(5):475-480.

Burton NC, Grinshpun SA, Reponen T [2006]. Physical collection efficiency of filter materials for bacteria and viruses. Ann Occup Hyg 51(2):143-151.

Cameron CE, Zuerner RL, Raverty S, Colegrove KM, Norman SA, Lambourn DM, Jeffries SJ, Gulland FM [2008]. Detection of pathogenic Leptospira bacteria in pinniped populations via PCR and identification of a source of transmission for zoonotic leptospirosis in the marine environment. J Clin Microbiol 46(5):1728-1733.

CDC [2012a]. Guidelines for safe work practices in human and animal medical diagnostic laboratories. MMWR 61:1-102.

CDC [2012b]. Brucellosis: General Information [http://www.cdc.gov/nczved/divisions/ dfbmd/diseases/brucellosis/\#four]. Date accessed: April 2013.

CDC [2012c]. Leptospirosis topic page. [http://www.cdc.gov/leptospirosis/]. Date accessed: April 2013.

Colegrove KM, Lowenstine LJ, Gulland FM [2005]. Leptospirosis in northern elephant seals (Mirounga angustirostris) stranded along the California coast. J Wildl Dis 41(2):426-430.

DHHS [2009]. Biosafety in microbiological and biomedical laboratories. 5th ed. Wilson DE, Chosewood LC, eds. Washington, DC: U.S. Department of Health and Human Services, Centers for Disease Control and Prevention, National Institutes of Health, HHS Publication No. (CDC) 21-1112. [http://www.cdc.gov/biosafety/publications/bmbl5/ BMBL.pdf]. Date accessed: April 2013. 
Dikken H, Kmety E [1978]. Serological typing methods of leptospires. In: Bergan T, JR Norris, editors. Methods in microbiology. London: Academic Press. pp. 259-307.

Duncan C, Kersh GJ, Spraker T, Patyk KA, Fitzpatrick KA, Massung RF, Gelatt T [2012]. Coxiella burnetii in northern fur seal (Callorhinus ursinus) placentas from St. Paul Island, Alaska. Vector Borne Zoonot Dis 12(3):192-195.

Ewalt DR, Payeur JB, Martin BM, Cummins DR, Miller GM [1994]. Characteristics of a Brucella species from a bottlenose dolphin (Tursiops truncatus). J Vet Diagn Invest $6(4): 448-452$.

Fitzpatrick KA, Kersh GJ, Massung RF [2010]. Practical method for extraction of PCRquality DNA from environmental soil samples. Appl Environ Microbiol 76(13):45714573.

Heymann DL, ed. [2004]. Control of communicable diseases manual. 18th ed. Washington DC: American Public Health Association, p. 435.

Hunt TD, Ziccardi MH, Gulland FMD, Yochem PK, Hird DW, Rowles T, Mazet JAK [2008]. Health risks for marine mammal workers. Dis Aquat Org 81(1):81-92.

Kersh GJ, Lambourn DM, Raverty SA, Fitzpatrick KA, Self JS, Akmajian AM, Jeffries SJ, Huggins J, Drew CP, Zaki SR, Massung RF [2012]. Coxiella burnetii infection of marine mammals in the Pacific Northwest, 1997-2010. J Wildl Dis 48(1):201-206.

Kersh GJ, Lambourn DM, Self JS, Akmajian AM, Stanton JB, Baszler TV, Raverty SA, Massung RF [2010]. Coxiella burnetii infection of a Steller sea lion (Eumetopias jubatus) found in Washington State. J Clin Microbiol 48(1):3428-3431.

Koch A, Svendsen CB, Christensen JJ, Bundgaard H, Vindfeld L, Christiansen CB, Kemp M, Villumsen S [2010]. Q fever in Greenland. Emerg Infect Dis 16(3):511-513.

Lapointe JM, Gulland FM, Haines DM, Barr BC, Duignan PJ [1999]. Placentitis due to Coxiella burnetii in Pacific harbor seal (Phoca vitulina richardsi). J Vet Diag Invest 11(6):541-543.

Levett P [2001]. Leptospirosis. Clin Microbiol Rev 14(2):296-326.

Lloyd-Smith JO, Greig DJ, Hietala S, Ghneim GS, Palmer L, Leger JS, Grenfell BT, Gulland FM [2007]. Cyclical changes in seroprevalence of leptospirosis in California sea lions: endemic and epidemic disease in one host species? BMC Infect Dis 7:125-135. 
McDonald WL, Jamaludin R, Mackereth G, Hansen M, Humphrey S, Short P, Taylor T, Swingler J, Dawson CE, Whatmore AM, Stubberfield E, Perrett LL, Simmons G [2006]. Characterization of a Brucella sp. strain as a marine-mammal type despite isolation from a patient with spinal osteomyelitis in New Zealand. J Clin Microbiol 44(12):4363-4370.

National Association of State Public Health Veterinarians (NASPHV) [2010]. Compendium of veterinary standard precautions for zoonotic disease prevention in veterinary personnel. JAVMA 237(12):1403-1422.

National Response Team [2011]. NRT quick reference guide: Brucella species (causes the disease brucellosis). [http://www.nrt.org/Production/NRT/NRTWeb.nsf/ AllAttachmentsByTitle/A-1009WMDQRGBrucellaSpecies/\$File/120502 Brucella QRG_Final.pdf?OpenElement]. Date accessed: April 2013.

NIOSH [1998]. Latex allergy a prevention guide. Cincinnati, OH: U.S. Department of Health and Human Services, Centers for Disease Control and Prevention, National Institute for Occupational Safety and Health, DHHS (NIOSH) Publication No. 98-113. [http://www.cdc.gov/niosh/docs/98-113/]. Date accessed: April 2013.

Ross HM, Foster G, Reid RJ, Jahans KL, MacMillan AP [1994]. Brucella species infection in sea mammals. Vet Rec 134(14):359.

Scott GH, Williams JC [2006]. Susceptibility of Coxiella burnetii to chemical disinfectants. Ann NY Acad Sci 560(1):291-296.

Smith AW, Brown RJ, Skilling DE, Bray HL, Keyes MC [1977]. Naturally-occurring leptospirosis in northern fur seals (Callorhinus ursinus). J Wildl Dis 13(2):144-148.

Sohn AH, Probert WS, Glaser CA, Gupta N, Bollen AW, Wong JD, Grace EM, McDonald WC [2003]. Human neurobrucellosis with intracerebral granuloma caused by a marine mammal Brucella spp. Emerg Infect Dis 9(4):485-488.

Stamper MA, Gulland FM, Spraker T [1998]. Leptospirosis in rehabilitated Pacific harbor seals from California. J Wildl Dis 34(2):407-410.

Sykes JE, Hartmann K, Lunn KF, Moore GE, Stoddard RA, Goldstein RE [2011]. 2010 ACVIM small animal consensus statement on leptospirosis: diagnosis, epidemiology, treatment, and prevention. J Vet Int Med 25(1):1-13.

Trout D, Gomez TM, Bernard BP, Mueller CA, Smith CG, Hunter, L, Kiefer M [1995]. Outbreak of brucellosis at a United States pork packing plant. J Occup Environ Med 37(6):697-703. 
Van Bressem MF, Raga JA, Di Guardo G, Jepson PD, Duignan PJ, Siebert U, Barrett T, Santos MC, Moreno IB, Siciliano S, Aguilar A, Van Waerebeek K [2009]. Emerging infectious diseases in cetaceans worldwide and the possible role of environmental stressors. Dis Aquat Organ 86(2):143-157.

van Woerden HC, Mason BW, Nehaul LK, Smith R, Salmon RL, Healy B, Valappil M, Westmoreland D, de Martin S, Evans MR, Lloyd G, Hamilton-Kirkwood M, Williams NS [2004]. Q fever outbreak in industrial setting. Emerg Infect Dis 10(7):12. 
Keywords: NAICS 813312 (Environment, Conservation and Wildlife Organizations), marine mammal, seal, sea lion, leptospirosis, brucellosis, Q fever, rehabilitation, rescue, Coxiella burnetii, Leptospira spp., Brucella spp., zoonotic infection, zoonoses. 
The Health Hazard Evaluation Program investigates possible health hazards in the workplace under the authority of Section 20(a)(6) of the Occupational Safety and Health Act of 1970, 29 U.S.C. 669(a)(6). The Health Hazard Evaluation Program also provides, upon request, technical assistance to federal, state, and local agencies to control occupational health hazards and to prevent occupational illness and disease. Regulations guiding the Program can be found in Title 42, Code of Federal Regulations, Part 85; Requests for Health Hazard Evaluations (42 CFR 85).

\section{Acknowledgments}

Analytical Support: Gilbert Kersh, Joshua Self, Kelly Fitzpatrick, and Robyn Stoddard, NCEZID

Desktop Publishers: Greg Hartle and Mary Winfree

Editor: Ellen Galloway

Health Communicator: Stefanie Brown

Industrial Hygiene Field Assistance: Joshua Self, NCEZID

Logistics: Donald Booher and Karl Feldmann

Medical Field Assistance: Barbara MacKenzie and Debbie Sammons; Ruchika Saini, formally with the University of Kentucky College of Medicine; Adam Bjork, CGH Medical Protocol Development: Alicia Anderson, NCEZID; Adam Bjork, CGH

\section{Availability of Report}

Copies of this report have been sent to the employer, employees, and union at the facility. The state and local health department and the Occupational Safety and Health Administration Regional Office have also received a copy. This report is not copyrighted and may be freely reproduced.

This report is available at http://www.cdc.gov/niosh/hhe/reports/pdfs/2011-0105-3173.pdf

\section{Recommended citation for this report:}

NIOSH [2013]. Health hazard evaluation report: evaluation of zoonotic disease and exposures in persons working with marine mammals. By Gibbins J, Niemeier RT, de Perio MA, Mueller C. Cincinnati, OH: U.S. Department of Health and Human Services, Centers for Disease Control and Prevention, National Institute for Occupational Safety and Health, NIOSH HETA No. 2011-0105-3173. 
Delivering on the Nation's promise:

Safety and health at work for all people through research and prevention

To receive NIOSH documents or more information about occupational safety and health topics, please contact NIOSH:

Telephone: 1-800-CDC-INFO (1-800-232-4636)

TTY: 1-888-232-6348

CDC INFO: www.cdc.gov/info

or visit the NIOSH Web site at www.cdc.gov/niosh

For a monthly update on news at $\mathrm{NIOSH}$, subscribe to $\mathrm{NIOSH}$ eNews by visiting www.cdc.gov/niosh/eNews.

SAFER • HEALTHIER $\cdot$ PEOPLE ${ }^{\text {TM }}$ 